\title{
Characterization of peppermint (Mentha piperita L.) essential oil encapsulates
}

\section{Murat Yilmaztekin, Steva Lević, Ana Kalušević, Mustafa Cam, Branko Bugarski, Vesna Rakić, Vladimir Pavlović \& Viktor Nedović}

To cite this article: Murat Yilmaztekin, Steva Lević, Ana Kalušević, Mustafa Cam, Branko Bugarski, Vesna Rakić, Vladimir Pavlović \& Viktor Nedović (2019): Characterization of peppermint (Mentha piperita L.) essential oil encapsulates, Journal of Microencapsulation, DOI: 10.1080/02652048.2019.1607596

To link to this article: https://doi.org/10.1080/02652048.2019.1607596

Accepted author version posted online: 13 Apr 2019.

Submit your article to this journal ๘

山 Article views: 25

View Crossmark data $₫$ 


\title{
Characterization of peppermint (Mentha piperita L.) essential oil encapsulates
}

\author{
Murat Yilmaztekin ${ }^{1 *}$, Steva Lević ${ }^{2}$, Ana Kalušević ${ }^{2}$, Mustafa Cam $^{3}$, Branko Bugarski ${ }^{4}$, \\ Vesna Rakić $^{2}$, Vladimir Pavlović ${ }^{2}$ and Viktor Nedović ${ }^{2}$
}

${ }^{1}$ Inonu University, Faculty of Engineering, Department of Food Engineering, 44280, Malatya, Turkey

${ }^{2}$ University of Belgrade, Faculty of Agriculture, Department of Food Technology and Biochemistry, Nemanjina 6, 11080 Belgrade-Zemun, Serbia

${ }^{3}$ Erciyes University, Faculty of Engineering, Department of Food Engineering, 38039, Kayseri, Turkey

${ }^{4}$ University of Belgrade, Faculty of Technology and Metallurgy, Department of Chemical Engineering, Karnegijeva 4, 11120 Belgrade, Serbia

*Corresponding author.

Murat Yilmaztekin

Inonu University, Faculty of Engineering, Department of Food Engineering, 44280, Malatya, Turkey

Phone: +904223774784

Fax: +90 4223410046

E-mail address: murat.yilmaztekin@ inonu.edu.tr

Running title: Peppermint (Mentha piperita L.) essential oil encapsulates 


\begin{abstract}
Aims: The aim was to choose the optimal encapsulation system and to incorporate encapsulates loaded with essential oil into ice cream as a model food product.

Methods: Ca-alginate beads were produced by electrostatic extrusion process. Gelatin/alginate coacervates were processed with coacervation. Carnauba wax microparticles were produced using melt dispersion process. Morphological properties, chemical and thermal stabilities of encapsulates were tested by SEM, FTIR spectral and thermogravimetric analysis.

Results: Alginate provided sufficient emulsion stability over $1 \mathrm{~h}$. Ca-alginate showed higher encapsulation efficiency $(98.4 \pm 4.3 \%)$ compared to carnauba wax $(94.2 \pm 7.8 \%)$ and gelatin/alginate coacervates $(13.2 \pm 1.2 \%)$. The presence of essential oil in the all three type of encapsulates confirmed with FTIR. The encapsulation process ensured controlled release and thermal stability of oil.

Conclusions: Ca-alginate matrix as the most suitable for peppermint essential oil encapsulation. The sensory analysis showed that ice cream incorporating encapsulates is promising system for consumption of health beneficial peppermint essential oil.
\end{abstract}

Keywords: Mentha piperita L. essential oil, encapsulation, ice cream, sensory evaluation 


\section{Introduction}

Essential oils have a huge historical and practical significance for human civilization, primarily as therapeutics for treatment of various diseases, as well as ingredients in cosmetics and food products (Burt, 2004). The peppermint is rich source of valuable natural compounds with antimicrobial, antioxidant and antitumor activity (McKay and Blumberg, 2006). Peppermint essential oil is traditionally produced and widely used in medicine, massage and for personal hygiene (Ody, 1993). Also, peppermint essential oils could be used as source of monoterpenes that are suitable for treatment of some cancers types (Crowell, 1997).

Due to exposure to unfavorable environmental conditions such as high temperatures or oxygen, the essential oils may lost their valuable ingredients and consequently their health benefits. Volatile and chemically unstable components of essential oils could be additionally protected by the process commonly known as encapsulation. Encapsulation could be defined as entrapping of active compound (core) into structure of another material (shell) (Gibbs et al., 1999). Numerous encapsulation techniques such as spray drying, fluid bed coating, spraycooling, melt injection, coacervation and encapsulation in polymer microsphere have been developed for encapsulation of food active compounds (Zuidam \& Shimoni, 2010). One of the promising encapsulation methods is entrapping of active compound inside polymer matrix. Among natural polymers, alginate has been intensively used for encapsulation of food additive (Manojlović et al., 2008) and essential oils (Chang \& Dobashi, 2003; Lai et al., 2007). Further, the size of alginate based encapsulates could be controlled using electrostatic droplet generation, enabling production of spherical calcium alginate particles suitable for various biotechnological applications (Nedović et al., 2001; Manojlović et al., 2008; Lević et al., 2013).

Another promising encapsulation technique for protection and controlled delivery of essential oils is coacervation. Encapsulates produced by coacervation (or simple coacervates) 
could be defined as encapsulation system produced by liquid-liquid phase separation of polymer(s) aqueous solution. By careful adjustment of temperature and $\mathrm{pH}$, it is possible to create polymer layer around dispersed oil droplets. After formation, coacervates are separated from solution and could be further processed by crosslinking of shell material or processing coacervates by drying (Zuidam \& Shimoni, 2010). Coacervation has been applied for encapsulation of aromatic compounds using different natural shell materials. Jun-xia et al. (2011) showed that coacervation between soybean protein isolate and gum arabic can be used for encapsulation of sweet orange oil into spherical shaped particles. Also, heat resistance of essential oil could be improved using coacervates based on gelatin/gum arabic (Lv et al., 2014).

Encapsulation of highly hydrophobic active materials such as essential oils could be achieved by applying hydrophobic shell material. This approach has been considered for encapsulation of pharmaceutical compounds inside hydrophobic natural compounds such as waxes. Usually, preparation of wax particles are based on dispersion of molten mixture wax/active compound in hot water followed with solidification by cooling and fast solidification of lipid carrier enables efficient entrapment of hydrophobic compounds inside wax microparticles (Milanović et al., 2010).

The aim of this study was to investigate the possible solutions for essential oils encapsulation. Peppermint essential oil was used in this study as model core compound, while Ca-alginate, gelatin/alginate and carnauba wax were carriers for encapsulation. In order to eliminate water and provide better storage performance on encapsulates, the samples were freeze dried..The morphology, chemical composition and thermal properties of encapsulates were studied in order to define optimal system for peppermint essential oil encapsulation. Considering potential health benefits of using peppermint essential oil in food industry, production of encapsulates were optimized in that respect that the final encapsulates could be 
applied in various food products. Carnauba wax beads loading peppermint essential oil were chosen as optimal encapsulation system and were incorporated into ice cream as a model food product. Sensory analysis was carried out on ice cream samples enriched with carnauba wax beads containing peppermint essential oil.

\section{Materials and methods}

\subsection{Materials}

Peppermint essential oil (Arifoglu brand) was supplied from a local market (Kayseri, Turkey). The chemical composition of essential oil determined by GC-MS was given in Table

1. The alginate (ALGOGEL ${ }^{\mathrm{TM}} 3001$, Cargill, Minnetonka, US) was generously donated by PALCO (Šabac, Serbia). Bovine gelatin (food grade) was supplied from domestic market in Belgrade (Serbia). Carnauba wax was supplied from Carl Roth GmbH (Karlsruhe, Germany). Sodium citrate and dichloromethane (GC grade) were obtained from Merck (Darmstadt, Germany). All other chemicals were of analytical reagent grade and used without any further purification.

\subsection{Encapsulation of peppermint essential oil in Ca-alginate beads}

The production of Ca-alginate beads was realized in two phases. First phase was preparation of liquid systems-emulsions that are used for beads production. Prior to preparation of emulsion, Na-alginate was dissolved in distilled water (concentration of 0.02 $\mathrm{g} / \mathrm{mL}$ ). Further, different ratios of peppermint essential oil to Na-alginate (10 and $20 \%$, w/w oil in alginate solution) were mixed in order to produce stable emulsions. The emulsions were prepared using mechanical stirrer Ultra-Turrax ${ }^{\circledR}$ T25 (Janke and Kunkel Ika-Labortechnik, Germany) at $10000 \mathrm{rpm}$ for 2 minutes. Emulsions prepared in this way remain stable over the $1 \mathrm{~h}$, which is period of time enough for emulsion extrusion and beads formation. The addition 
of emulsifiers was not necessary since alginate provided sufficient emulsion stability, which is in accordance with previously reported results (Lević et al., 2015).

In the second phase, the Ca-alginate beads with encapsulated peppermint essential oil were produced by procedure described previously by Nedović et al. (2001). Droplets were formed by extrusion of the sodium alginate/essential oil emulsion through a blunt stainless steel needle using a syringe pump (Pump 11, Harvard Apparatus, US). The needle was grounded, while the collecting solution $\left(\mathrm{CaCl}_{2}\right.$ in water, $\left.0.015 \mathrm{~g} / \mathrm{mL}\right)$ was positively charged. Beads production was carried out by applying electrostatic potentials of $8 \mathrm{kV}$. Electrostatic encapsulation unit (VAR V1, Nisco Engineering Inc., Zurich, Switzerland) was used in this work for beads production under electrostatic potential. The distance between the needle tip (id: $0.7 \mathrm{~mm}$ ) and the collecting solution was $2.5 \mathrm{~cm}$, while the flow rate of the liquid was 70 $\mathrm{mL} / \mathrm{h}$. After formation of the beads, they were left in hardening solution without stirring for $60 \mathrm{~min}$ in order to assure finishing of the gelling process. The formed alginate beads were removed from the $\mathrm{CaCl}_{2}$ solution by filtration and washed with distillated water. After gel formation period, the beads were frozen at $-20^{\circ} \mathrm{C}$ overnight before freeze drying, which was carried out at $-50{ }^{\circ} \mathrm{C}$ at a pressure of $1.1 \mathrm{~Pa}$ for $24 \mathrm{~h}$ in freeze drier (GAMMA Martin Christ, GmbH, Osterode am Harz, Germany).

\subsection{Encapsulation of peppermint essential oil in gelatin/alginate coacervates}

Formation of coacervates loading peppermint essential oil was performed according to procedure described by Siow and Ong (2013), with modifications. The main modifications were usage of Na-alginate as carrier material and citric acid for $\mathrm{pH}$ control instead of gum arabic and acetic acid, respectively. Gelatin (concentration of $0.02 \mathrm{~g} / \mathrm{mL}$ ) and Na-alginate solutions (concentration of $0.02 \mathrm{~g} / \mathrm{mL}$ ) were prepared by dissolving these compounds in distilled water. $25 \mathrm{~mL}$ of each gelatin and Na-alginate solutions were mixed with 1,2 and $4 \mathrm{~g}$ 
of essential oil at $45{ }^{\circ} \mathrm{C}$ by a mechanical stirrer Ultra-Turrax ${ }^{\circledR}$ T25 (Janke and Kunkel IkaLabortechnik, Germany), respectively. A solution of $10 \%(w / v)$ citric acid was added to mixture to adjust $\mathrm{pH}$ to 2-3. Such relatively low $\mathrm{pH}$ was applied in order to ensure fast coacervates formation and to minimize the loss of essential oil during preparation steps. The mixture was cooled down immediately to $10{ }^{\circ} \mathrm{C}$ in an ice bath. Further, the coacervates were collected by filtration, washed with distillated water and freeze dried as described above.

\subsection{Encapsulation of peppermint essential oil in carnauba wax}

Encapsulation of peppermint essential oil in carnauba wax was realized by melt dispersion technique (Milanović et al., 2010). Carnauba wax was melted in distilled water at $95{ }^{\circ} \mathrm{C}$ in a water bath. Peppermint oil was added to the dispersion of molten wax in water while stirring rigorously (10000 rpm for $2 \mathrm{~min}$ ) by a mechanical stirrer Ultra-Turrax ${ }^{\circledR}$ T25 (Janke and Kunkel Ika-Labortechnik, Germany). Different weight ratios of essential oil to wax $(10,20$, 30 and $50 \%, \mathrm{w} / \mathrm{w}$ ) were tested. The solidification of the molten wax droplets with oil were performed by adding $150 \mathrm{~mL}$ of cold water $\left(\sim 5^{\circ} \mathrm{C}\right)$ to the resulting dispersion. After addition of cold water, dispersion was cooled down and solid particles were formed. Further, the particles were collected by filtration, washed with distilled water and freeze dried. All encapsulates were then stored at $+4{ }^{\circ} \mathrm{C}$ in closed falcon tubes for further analyses.

\subsection{Analysis of the bead dimensions and shape}

Dimension and shape of wet and dried Ca-alginate beads as well as carnauba wax particles were evaluated by binocular microscope Leica XTL-3 400D (Leica, Germany), equipped with camera (DC 300, Leica, Germany) and software for measuring (IM 1000, Leica, Germany). For each measurement, a sample of 30 beads was taken and the diameters of the beads were 
measured. The diameter for each particle was calculated as average of the horizontal and perpendicular dimensions (Lević et al., 2015).

\subsection{Scanning electron microscopy (SEM)}

Morphological investigations of the samples surface have been carried out by JEOL JSM6390LV scanning electron microscope. Prior to analysis, samples were sputter-coated with gold during 100 seconds under 30mA ion current on BALTEC SCD 005 sputter coater (Lević et al., 2015).

\subsection{Determination of encapsulation efficiency}

Encapsulation $(E E)$ efficiency of encapsulates were calculated by the following equation as the percentage of the total amount of encapsulated essential oil $\left(m_{E}\right)$ in the total amount of initial input of essential oil $\left(m_{I}\right)$ (Lević et al., 2015; Siow and Ong, 2013):

$$
E E(\%)=\left(m_{E} / m_{I}\right) * 100
$$

Quantification of essential oil content in encapsulates was performed after extraction with dichloromethane. Briefly, $0.5 \mathrm{~g}$ of lyophilised alginate encapsulate was dissolved in $40 \mathrm{~mL}$ of sodium citrate water solution $(1.5 \%, \mathrm{w} / \mathrm{v})$ in a sealed glass bottle under vigorous mixing using a vortex mixer. When encapsulates are dissolved, $5 \mathrm{ml}$ of dichloromethane was added and essential oil was extracted for 15-20 min with intermittent mixing. For carnauba wax and coacervates based on gelatin, $0.5 \mathrm{~g}$ of encapsulate was extracted three times with $10 \mathrm{~mL}$ portions of dichloromethane. After extraction organic phase was separated and subjected to GC-MS analysis. 


\subsection{GC-MS analysis of peppermint essential oil}

Gas chromatography-mass spectrometry (GC-MS) analysis was performed in order to determine the composition of peppermint essential oil and to measure the concentration of the most represented compound, menthol, in dichloromethane extracts of encapsulates which is used for calculation of encapsulation efficiencies. The analyses were carried out on a Shimadzu QP 2010 Plus (Shimadzu, Kyoto, Japan) GC equipped with an AOC-20i/20s autosampler and a MS-QP 2010 series mass-selective detector. The conditions of GC-MS were adapted from Yilmaztekin (2014). Sample $(1 \mu \mathrm{L})$ was injected into the injector with a split ratio of 1:50. Volatile compounds were separated with a TRB-Wax (Teknokroma, Barcelona, Spain $)$ fused silica capillary column $(60 \mathrm{~m} \times 0.25 \mathrm{~mm}$ i.d. and $0.25 \mu \mathrm{m}$ film thickness). Helium was used as the carrier gas at a flow rate of $1 \mathrm{~mL} / \mathrm{min}$. The column was maintained at $40{ }^{\circ} \mathrm{C}$ for $5 \mathrm{~min}$ after injection, and then programmed at $3{ }^{\circ} \mathrm{C} / \mathrm{min}$ to $240{ }^{\circ} \mathrm{C}$, which was maintained for $15 \mathrm{~min}$. The total run time, including oven cooling, was 86 min. Injector, transfer line, and ion-source temperatures were maintained at $250{ }^{\circ} \mathrm{C}$. Mass spectrums were acquired in electron-impact (EI) mode; the ionization voltage was $70 \mathrm{eV}$; the mass range was $35-450 \mathrm{~m} / \mathrm{z}$; scanning rate was $1 \mathrm{scan} / \mathrm{s}$. A mixture of n-alkanes $\left(\mathrm{C}_{8}-\mathrm{C}_{28}\right)$ was injected under the above conditions to calculate the linear retention indexes (as Kovats' indice, I) of each compound. The identification was made by comparison of the obtained mass spectrums of the relevant chromatographic peaks with spectrums of the NIST (National Institute of Standards and Technology, Gaithersburg, MD, USA) and Wiley libraries. In addition, tentative identification was carried out by comparing the experimental retention indices with the theoretical ones obtained from the NIST Standard Reference Database (NIST 2013). Quantitative analysis of essential oil components (expressed as area percentage) was carried out by peak area normalization measurement. Menthol was identified by comparing 
the retention times and spectral data with those of the appropriate standard. The amount of essential oil in beads was calculated by calibration curve obtained from dichloromethane extracts of known amounts of essential oil.

\subsection{FTIR spectral analysis}

FTIR spectra of the freeze dried encapsulates was studied using IRAffinity-1 (SHIMADZU) FTIR spectrometer. Spectra were collected using $\mathrm{KBr}$ pellets (1 mg of sample in $200 \mathrm{mg}$ of $\mathrm{KBr}$ ) in the spectral range $4000-600 \mathrm{~cm}^{-1}$. Spectra were recorded as average curves from 20 acquisitions, with the resolution of $4 \mathrm{~cm}^{-1}$ (Lević et al., 2013). FTIR spectra of free peppermint essential oil $(2 \mu \mathrm{L})$ were recorded using two blank $\mathrm{KBr}$ tablets that were used to create a thin liquid sample film.

\subsection{Thermal analysis of the samples}

Thermal analyses of freeze dried samples were carried out in a Setaram's system TG/DSC111. The measurements were realized under dynamic oxygen of a flow rate of 30 $\mathrm{mL} / \mathrm{min}$ (pressure $1 \mathrm{~atm}$ ) using a heating rate of $10{ }^{\circ} \mathrm{C} / \mathrm{min}$ from 50 to $300{ }^{\circ} \mathrm{C}$.

\subsection{Production of ice cream incorporated with carnauba wax oil beads}

Due to small size of the particles and relatively satisfactory encapsulation efficiency, carnauba wax based encapsulates were chosen for incorporation into ice cream. Although Caalginate capsules exhibited better encapsulation efficiency (see below), their size could negatively affect ice cream textural properties and overall sensorial acceptance. Four types of ice cream were produced with the following combinations according to Cam et al. (2013): Control ice cream (IC1), enriched with peppermint oils at $0.1 \%(\mathrm{w} / \mathrm{w})(\mathrm{IC} 2), 0.2 \%(\mathrm{w} / \mathrm{w})$ (IC3) and $0.3 \%(\mathrm{w} / \mathrm{w})(\mathrm{IC} 4)$. The amount of peppermint oil in the samples was based on dry 
matter content. As an example, ice cream ingredients for IC2 were mixed in the following combinations: A glass beaker containing $180 \mathrm{~mL}$ of skim milk was place on a thermostatically controlled mechanical stirrer. Ingredients were added into the beaker at $50{ }^{\circ} \mathrm{C}$ with regular stirring at $1000 \mathrm{rpm}$. Cream (40 g), skim milk powder (25 g), sucrose (32 g), mono-di glyceride mix $(0.5 \mathrm{~g})$, sahlep as stabilizer $(0.5 \mathrm{~g})$ and encapsulated peppermint oil $(0.1 \mathrm{~g})$. The mixture was pasteurized at $80{ }^{\circ} \mathrm{C}$ for $10 \mathrm{~min}$ followed by cooled to $+4{ }^{\circ} \mathrm{C}$. After keeping the mixture at $+4{ }^{\circ} \mathrm{C}$ for $24 \mathrm{~h}$ the aged mixture was whipped at $0{ }^{\circ} \mathrm{C}$ for 30 min with a laboratory type ice cream machine (Gelato, Bologna, Italy). The resulting ice cream was hardened at $-18{ }^{\circ} \mathrm{C}$ for $24 \mathrm{~h}$ in a deep freezer. All other formulations (IC1, IC3, and IC4) were prepared in the same way by changing the peppermint oil content but keeping the amount of other ingredient's constant.

\subsection{Quantitative descriptive sensory analysis of ice cream incorporated with carnauba wax} oil beads

Six nonsmoking panelists had previous experience in testing ice cream (3 female and 3 male, ages between 26 and 39) from Department of Food Engineering in Erciyes University were selected for the evaluation of the sensory attributes of the ice creams. The panelists were trained until they fully understood the sensory terms of ice creams and showed consistent replicates. Reference sample preparation and administration of the panel were conducted according to relevant literature (Hightower and Edgar, 2009; Soukoulis and Tzia 2010; Cam et al., 2013).

Flavor descriptors of ice creams were selected as: palatable, sweet, sour, astringent, and peppermint flavor. A 10-point scale was used for evaluations, where 0 for nonexistence, 5 for imperceptible, 10 for strong presence of related attributes. The definitions of the descriptors and sample references are given in Table 2. 


\subsection{Statistical analysis}

All chemical and instrumental analyses were done minimum in triplicate. Ice cream formulations were prepared minimum in duplicate. Analysis of variance was performed to determine significant differences between the shell materials for bead sizes and encapsulation efficiencies at $P \leq 0.05$ significant level using the SPSS 17.0.1 statistical package for Windows (SPSS Inc., Chicago, Ill., U.S.A.).

\section{Results and discussion}

\subsection{Bead size, encapsulation loading and encapsulation efficiency of peppermint} essential oil encapsulates

Ca-alginate, gelatin/alginate coacervates and carnauba wax microparticles were used as carriers for encapsulation of peppermint essential oil. Table 3 shows the average size and encapsulation efficiencies of peppermint essential oil encapsulates.

As can be seen, Ca-alginate as carrier material showed higher encapsulation efficiency $(98.4 \pm 4.3 \%)$, followed by carnauba wax microparticle $(94.2 \pm 7.8 \%)$, while gelatin/alginate coacervates exhibited the lowest encapsulation efficiency $(13.2 \pm 1.2 \%)$. These results are in accordance with the results from other authors who also reported high encapsulation efficiency of Ca-alginate and carnauba wax as carriers for encapsulation of hydrophobic compounds (Lević et al., 2015; Milanović et al., 2010). Evidently, gelatin/alginate coacervates are far less suitable for encapsulation of peppermint essential oil regarding encapsulation efficiency. This is contrast to results reported in other studies that usually showed high encapsulation efficiency of coacervates loading essential oils and aromatic compounds (Manaf et al., 2018). Low encapsulation efficiency of the gelatin/alginate coacervates prepared in this study could be explained by repulsive forces between hydrophilic 
carriers and essential oil as well as complex structure of peppermint essential oil. Also, McClements and Rao (2011) pointed out that formation of stable emulsion of essential oil is difficult process since smaller oil droplets tend to coalescence into larger droplets, leading to emulsion breakdown. Furthermore, additional processing of coacervates such as drying may cause further loss of essential oil. This was observed by Shinde \& Nagarsenker (2011) for the gelatin/alginate coacervates loading eugenol. The same authors reported similar encapsulation efficiency as we observed in this study, and as the main reasons for low retention of eugenol they suggested the dehydration of coacervates which caused structural changes of particles causing eugenol leakage.

The particles of Ca-alginate are larger compared to wax particles, while gelatin/alginate coacervates after drying were in the form of aggregated mass that could not be studied for their size.

\subsection{Morphological properties of peppermint essential oil encapsulates}

Morphological properties of encapsulates loading peppermint essential oil were studied by scanning electron microscopy and results are presented in Figure 1. After encapsulation and gelling process, wet $\mathrm{Ca}$-alginate beads exhibited spherical shape. However, during the freeze drying, the water were removed from the beads and the alginate matrix shrank significantly (Figure 1a, b).

According to Lević et al. (2013) addition of solid flavor into alginate matrix provide better preservation of beads shape and sphericity during drying process. It seems that solid filers (i.e. active compounds) are more suitable for shape stabilization of encapsulate compared to liquid active compounds. In some cases, preservation spherical shape of encapsulate is favorable (e.g. positive visual effects on consumers). Introduction of additional filer in formulation could be solutions for problem of shape maintenance during drying of alginate 
based spherical beads. Chan et al. (2011) proposed using of starch as filler substance for shape preservation of lyophilized Ca-alginate beads loading cells.

As we pointed out above, freeze dried coacervates (Figure 1c,d) show significant changes of morphological properties during drying process. Namely, after encapsulation, coacervates remained free flowing in working solutions and were easily collected. During drying process, the structure of coacervates changes toward compact-flakes like structure. On the other hand, microparticles based on carnauba wax (Figure 1e) show more regular spherical shape compared to other formulations, although their sizes were not uniform. According to Milanović et al. (2010) the size of carnauba wax microparticles produced by melting dispersion technique could be controlled by variation of process conditions. Compared to other formulations (i.e. Ca-alginate and gelatin/alginate coacervates) carnauba wax particles exhibit significant surface porosity (Figure 1f). Porosity of wax microparticles is most probably consequence of essential oil addition that causes changes of particles structure during encapsulation. Irregular surface of carnauba wax particles was also observed by Milanović et al. (2010).

\subsection{The results of FTIR analysis}

The FTIR spectra of the free peppermint essential oil and encapsulate loading oil are presented in Figure 2. In the spectrum of free essential oil, the strong band at $3470 \mathrm{~cm}^{-1}$ is assigned to the vibrations of the $-\mathrm{OH}$ groups, while bands at $2924 \mathrm{~cm}^{-1}$ and $2854 \mathrm{~cm}^{-1}$ appeared due to the presence of the $-\mathrm{CH}_{3}$ and $-\mathrm{CH}_{2}$ groups. The bands in the spectral range $1700-1750 \mathrm{~cm}^{-1}$ are most probably related to $\mathrm{C}=\mathrm{O}$ vibrations. Other band such as those at $1460 \mathrm{~cm}^{-1}$ and $1377 \mathrm{~cm}^{-1}$ originate from various organic compounds, which presence in the peppermint essential oil was verified by GC/MS analysis (see Table 1). Prakash and Yunus (2013) showed that vibrations assigned to menthol and menthone (in the spectral range 2849- 
$2954 \mathrm{~cm}^{-1}$ ), dominate in the FTIR spectrum of essential oil produced by hydro-distillation of Mentha arvensis. We also observed similar prominent bands in the same spectral region of both free and encapsulated peppermint essential oil. Also, the results of GC/MS analysis of Mentha piperita L. essential oil conducted in this study suggest that these two compounds are present in the high concentration.

The results of FTIR analysis show the presence of essential oil in the all three type of encapsulates produced in this study. Moreover, the spectra of carriers (i.e. Ca-alginate, gelatin/alginate coacervates and carnauba wax) are generally overlapped by spectrum of essential oil. Some relatively small variations in the spectra of encapsulate such as differences in bands shapes or intenisties might be due to carrier/oil bands overlapping. These findings clearly show that essential oil and carrier materials most probably made a simple mixture in the encapsulates, since there is no strong evidence of chemical interactions between peppermint essential oil compounds and carrier materials.

\subsection{The results of thermogravimetric analysis}

Thermal stability of free and encapsulated peppermint essential oil was investigated by thermogravimetry and results are presented in Figure 3. Free peppermint essential oil shows first mass loss in the temperature region $90-200^{\circ} \mathrm{C}(\sim 50 \%$ of mass loss). In the second temperature region, between $200^{\circ} \mathrm{C}$ and $300^{\circ} \mathrm{C}$ up to $\sim 60 \%$ of essential oil evaporates. The two steps in the TGA thermogram are most probably result of different boiling points of essential oil compounds. Also, it could be expected that some essential oil compounds are thermal decomposed to the new compounds. According to Neuenschwander et al. (2010), $\alpha$ pinene autoxidation under elevated temperature leads to formation of different types of peroxyl radicals. Further, peroxyl radicals' reaction leads to production of hydroperoxide or epoxide and alkoxyl radicals. 
In the case of Ca-alginate/essential oil, thermogram shows that up to $150^{\circ} \mathrm{C}$ the mass loss of beads is $<10 \%$. Further, mass loss is most probably connected with oil compounds evaporation/thermal decomposition as well as Ca-alginate thermal decomposition. The release of encapsulated peppermint essential oil and thermal decomposition of Ca-alginate matrix most probably occurred in the close temperature regions. According to Lević et al. (2013), the main mass losses of empty Ca-alginate beads correspond with two temperature regions: (i) 50-150 ${ }^{\circ} \mathrm{C}$ and (ii) $150-300^{\circ} \mathrm{C}$. Laurienzo et al. (2005) pointed out that mass loss in the first temperature region is connected with loss of water from alginate matrix. The second temperature region corresponds with mass loss of encapsulated oil (and most probably with oil thermal degradation) and with thermal decomposition of Ca-alginate. However, thermal degradation of alginate is complex process including several steps.

The TGA thermogram of encapsulated peppermint essential oil in gelatin/alginate coacervates shows two main mass losses. Up to $175^{\circ} \mathrm{C}$ the mass loss is $10-15 \%$ and most probably is connected with water loss from matrix material as well as essential oil release. In the temperature region from $50^{\circ} \mathrm{C}$ to $175^{\circ} \mathrm{C}$, the mass loss of coacervates with encapsulated oil is very similar to those based on Ca-alginate. However, at the end of analysis (at $300^{\circ} \mathrm{C}$ ), the coacervates show higher mass loss ( $\sim 70 \%$ mass loss $)$ than systems based on Ca-alginate (i.e. $\sim 50 \%$ mass loss).

Coacervates showed lower encapsulation efficiency compared to encapsulate produced by other encapsulation methods used in this study (see Table 2). As result, the kinetic of mass loss of coacervates at high temperatures is most probably affected by low essential oil content. Also, the reason for difference in the thermal properties of alginate beads and coacervates may be the fact that $\mathrm{Ca}$-alginate beads are produced by gelling of sodium alginate using $\mathrm{Ca}^{2+}$ ions as crosslinker. Thus, Ca-alginate is most probably more thermal stable matrix compared to gelatin/alginate coacervates that are not crosslinked. Devi et al. (2012) suggested 
that additional crosslinking using glutaraldehyde as crosslinker provides better thermal properties of gelatin/alginate microcapsules produced by complex coacervation. However, the usage of glutaraldehyde is limited in food industry. This problem could be for example solved by using enzymatic crosslinking of gelatin (Prata et al., 2008).

The thermogram of wax based encapsulates exhibit two mass losses: up to $\sim 250^{\circ} \mathrm{C}$ (max. at $130^{\circ} \mathrm{C}$, probably wax decomposition and oil release); the second mass loss occurs above $250^{\circ} \mathrm{C}$ and it is most probably connected with decomposition of carnauba wax. The release of essential oil is more pronounced at higher temperatures (above $80-85^{\circ} \mathrm{C}$ ) as melting point of carnauba wax corresponding to this temperature range. Milanović et al. (2010) noticed that thermal processes above $250^{\circ} \mathrm{C}$ are results of carnauba wax transformation under the high temperatures. Since wax particles under elevated temperature (i.e. $80-85^{\circ} \mathrm{C}$, carnauba wax melting point) are melted, such wax-based encapsulates are more suitable for applications in the low temperature food processes. We've selected ice cream as model food for incorporation and sensory analysis of peppermint oil encapsulated in the carnauba wax particles. Based on thermal analysis, the alginate and coacervates encapsulates of peppermint essential oil are more suitable for applications in the high temperature food processes (e.g. baker's products). Also, smaller in size, carnauba microparticles are more suitable regarding ice cream textural properties.

Thermal analyses showed that encapsulated essential oil was released at elevated temperatures in the broader temperature regions and in more controllable manner compared to free peppermint essential oil. These results suggest that encapsulated peppermint essential oil is most probably more suitable for thermal food processes, enabling protection and controlled release of aromatic compound into product. In this study, we tested applications of carnauba wax microparticles loading peppermint essential oil in ice cream. However, further studies are 
necessary in order to evaluate applications of encapsulated peppermint essential oil in other thermal processed food products.

\subsection{Quantitative descriptive sensory evaluation of ice cream incorporated with carnauba wax} oil beads

Ice cream samples, control and enriched with peppermint oil, showed no statistically significant differences in terms of textural properties and color in quantitative descriptive sensory analysis. There were no differences among 4 ice cream types in terms of textural properties e.g. hardness, coarseness, gumminess, iciness, wateriness, and creaminess. The same situation was observed for color as well. Therefore, texture and appearance of ice cream samples were not included here.

The increase in the amount of peppermint oil in ice creams imparted peppermint oil flavor to the samples (Figure 4). Sourness and astringency of ice creams were slightly perceived by the panelists, however, the degree of sourness and astringency were lower than the value of 4 . Refreshing peppermint oil flavor were noted aftertaste by the panelists. Panelists rated the overall acceptability of all peppermint oil enriched ice creams higher than the value of 7 . Therefore, peppermint oil enrichment might be a suitable option to produce new ice cream types. We have also tested the possibility of peppermint oil enrichment higher than $0.3 \%$ (w/w) in ice cream, however, oral burn and dramatic decrease in the overall acceptability were noted by panelists.

\section{Conclusions}

Ca-alginate encapsulates showed higher encapsulation efficiencies compared to other shell materials. On the other hand, after the drying process carnauba wax microparticles were more regular spherical in shape than the other formulations. The essential oil and carrier materials 
formed simple mixtures inside the encapsulates, without strong chemical interactions. The results of thermal analysis showed that encapsulation of peppermint essential oil ensured controlled release of oil in the broader temperature regions compared to free oil. According to sensory analysis, incorporation peppermint oil into ice cream up to $0.3 \%(\mathrm{w} / \mathrm{w})$ might be a suitable option to add functional properties of peppermint into ice cream without damaging textural properties. Since tested encapsulation systems are different in many aspects, our goal was to establish different procedures for essential oils encapsulation and to open the possibility for their application in encapsulated forms in food products. Regarding encapsulation efficiency, Ca-alginate is the most promising system for peppermint essential oil encapsulation. On the other hand, carnauba wax microparticles are suitable in the applications were small particles are required due to food textural properties (i.e. here tested ice cream with added carnauba wax microparticles loading peppermint essential oil). Coacervates showed the lowest encapsulation efficiency. However, due to its simple preparation procedure, encapsulation of essential oils by coacervation could be improved by additional steps like a crosslinking of carrier material in order to increase encapsulation efficiency.

\section{Acknowledgements}

This study was carried out in the framework of COST Action FA0907 BIOFLAVOUR under the EU's Seventh Framework Programme for Research (FP7) and supported by Ministry of Science and Technological Development, Republic of Serbia (Project nos. III46010 and III46001).

\section{The Authors declare that there is no conflict of interest.}




\section{References}

Burt, S. (2004). Essential oils: their antibacterial properties and potential applications in foods-a review. International Journal of Food Microbiology, 94, 223-253.

Çam, M.. Erdoğan, F.. Aslan, D., \& Dinç, M. (2013). Enrichment of functional properties of ice cream with pomegranate by-products. Journal of Food Science, 78, C1543-C1550.

Chan, E.S., Wong, S.L., Lee, P.P., Lee, J.S., Ti, T.B., Zhang, Z., Poncelet, D., Ravindra, P., Phan, S.H., \& Yim, Z.H. (2011). Effects of starch filler on the physical properties of lyophilized calcium-alginate beads and the viability of encapsulated cells. Carbohydrate Polymers, 83, 225-232.

Chang, P.C., \& Dobashi, T. (2003). Preparation of alginate complex capsules containing eucalyptus essential oil and its controlled release. Colloids and Surfaces B: Biointerfaces, 32, 257-262.

Crowell, P. (1997). Monoterpenes in breast cancer chemoprevention. Breast Cancer Research and Treatment, 46, 191-197.

Devi, N., Hazarika, D., Deka, C., \& Kakati, D.K. (2012). Study of Complex Coacervation of Gelatin A and Sodium Alginate for Microencapsulation of Olive Oil. Journal of Macromolecular Science, Part A. Pure and Applied Chemistry, 49, 936-945.

Gibbs, F.B., Kermasha, S., Alli, I., \& Mulligan, N.C. (1999). Encapsulation in the food industry: a review. International Journal of Food Sciences \& Nutrition, 50, 213-224.

Hightower, C.A., \& Edgar Iv, C. (2009). Descriptive sensory analysis of toothpaste flavor and texture using two sampling methods: Brushing versus spoon tasting. Journal of Sensory Studies, 24, 301-316.

Jun-xia, X., Hai-yan, Y., \& Jian, Y. (2011). Microencapsulation of sweet orange oil by complex coacervation with soybean protein isolate/gum Arabic. Food Chemistry, 125, 12671272. 
Lai, F., Loy, G., Manconi, M., Manca, L. M., \& Fadda, A.M. (2007). Artemisia arborescens 1 essential oil loaded beads: Preparation and Characterization. AAPS PharmSciTech, 8, E126-E132.

Laurienzo, P., Malinconico, M., Motta, A., \& Vicinanza, A. (2005). Synthesis and characterization of a novel alginate-poly(ethylene glycol) graft polymer. Carbohydrate Polymers, 62, 274-282.

Lević, S., Djordjević, V., Rajić, N., Milivojević, M., Bugarski, B., Nedović, V. (2013). Entrapment of ethyl vanillin in calcium alginate and calcium alginate/poly(vinyl alcohol) beads. Chemical Papers, 67 (2), 221-228.

Lević, S., Lijaković, I.P., Djordjević, V., Rac, V., Rakić, V., Knudsen, T.Š., Pavlović, V, Bugarski, B., \& Nedović, V. (2015). Characterization of sodium alginate/D-limonene emulsions and respective calcium alginate/D-limonene beads produced by electrostatic extrusion. Food Hydrocolloids, 45, 111-123.

Lv, Y., Yang, F., Li, X., Zhang, X., \& Abbas, S. (2014). Formation of heat-resistant nanocapsules of jasmine essential oil via gelatin/gum arabic based complex coacervation. Food Hydrocolloids, 35, 305-314.

Manaf, M.A., Subuki, I., Jai, J., Raslan, R. \& Mustapa, A.N. (2018). Encapsulation of Volatile Citronella Essential Oil by Coacervation: Efficiency and Release Study. IOP Conf. Series: Materials Science and Engineering, 358, 012072.

Manojlović, V., Rajić, N., Djonlagić, J., Obradović, B., Nedović, V., \& Bugarski, B. (2008). Application of electrostatic extrusion-flavour encapsulation and controlled release. Sensors, 8, 1488-1496.

McKay, L.D., \& Blumberg, B.J. (2006). A Review of the Bioactivity and Potential Health Benefits of Peppermint Tea (Mentha piperita L.). Phytotherapy Research, 20, 619-633. 
McClements, D.J., \& Rao, J. (2011). Food-Grade Nanoemulsions: Formulation, Fabrication, Properties, Performance, Biological Fate, and Potential Toxicity. Critical Reviews in Food Science and Nutrition, 51, 285-330.

Milanović, J., Manojlović, V., Lević, S., Rajić, N., Nedović, V., \& Bugarski, B. (2010). Microencapsulation of Flavors in Carnauba Wax. Sensors, 10, 901-912.

Nedović, V. A., Obradović, B., Leskošek-Čukalović, I., Trifunović, O., Pešić, R., \& Bugarski, B. (2001). Electrostatic generation of alginate microbeads loaded with brewing yeast. Process Biochemistry, 37, 17-22.

Neuenschwander, U., Guignard, F., \& Hermans, I. (2010). Mechanism of the Aerobic Oxidation of $\alpha$-Pinene. ChemSusChem, 3, 75-84.

Ody, P. (1993). The Complete Medicinal Herbal. (pp.79). Dorling Kindersley Limited, London.

Prakash, N., \& Yunus, M. (2013). Fourier Transform Infrared Spectroscopy Analysis of Oil of Mentha arvensis Grown at Sites Varying With Vehicular Traffic Loads in Lucknow city, India. International Journal of Environment, 2 (1), 16-25.

Prata, S.A., Zanin, H.A.M., Ré, I.M., \& Grosso, R.F.C. (2008). Release properties of chemical and enzymatic crosslinked gelatin-gum Arabic microparticles containing a fluorescent probe plus vetiver essential oil. Colloids and Surfaces B: Biointerfaces, 67, 171178.

Shinde, U. \& Nagarsenker, M. (2011). Microencapsulation of Eugenol by Gelatin-Sodium Alginate Complex Coacervation. Indian Journal of Pharmaceutical Sciences, 73, 311-315.

Siow, L.F., \& Ong, C.S. (2013). Effect of pH on Garlic Oil Encapsulation by Complex Coacervation. Journal of Food Processing and Technology, 4, 199. 
Soukoulis, C., \& Tzia, C. (2010). Response surface mapping of the sensory characteristics and acceptability of chocolate ice cream containing alternate sweetening agents. Journal of Sensory Studies, 25, 50-75.

Yilmaztekin, M. (2014). Characterization of potent aroma compounds of cape gooseberry (Physalis peruviana L.) fruits grown in antalya through the determination of odor activity values. International Journal of Food Properties, 17, 469-480.

Zuidam, N.J. \& Shimoni, E. (2010). Overview of Microencapsulates for Use in Food Products or Processes and Methods to Make Them. In: Zuidam, N.J., Nedovic, V.A., (Eds.). Encapsulation Technologies for Food Active Ingredients and Food Processing (pp. 3-31). Springer, Dordrecht, The Netherlands.

\section{Figure captions}

Fig. 1. SEM images: A2 (a-low magnification; b-high magnification), C4 (c-low magnification; d-high magnification), CW4 (e-low magnification; f-high magnification).

Fig. 2. FTIR spectrum of the free peppermint essential oil (a), A2 (b), C4 (c) and CW4 (d).

Fig. 3. Thermogravimetric analyses of essential oil (a), A2 (b), C4 (c) and CW4 (d). Black line-thermogravimetry curve; red line-differential thermal gravimetry curve.

Fig. 4. Sensory scores of ice cream samples in a radar plot (IC1: Control ice cream, IC2, IC3, and IC4: Ice cream enriched with peppermint oil at $0.1,0.2$ and $0.3 \%, \mathrm{w} / \mathrm{w}$, respectively). 

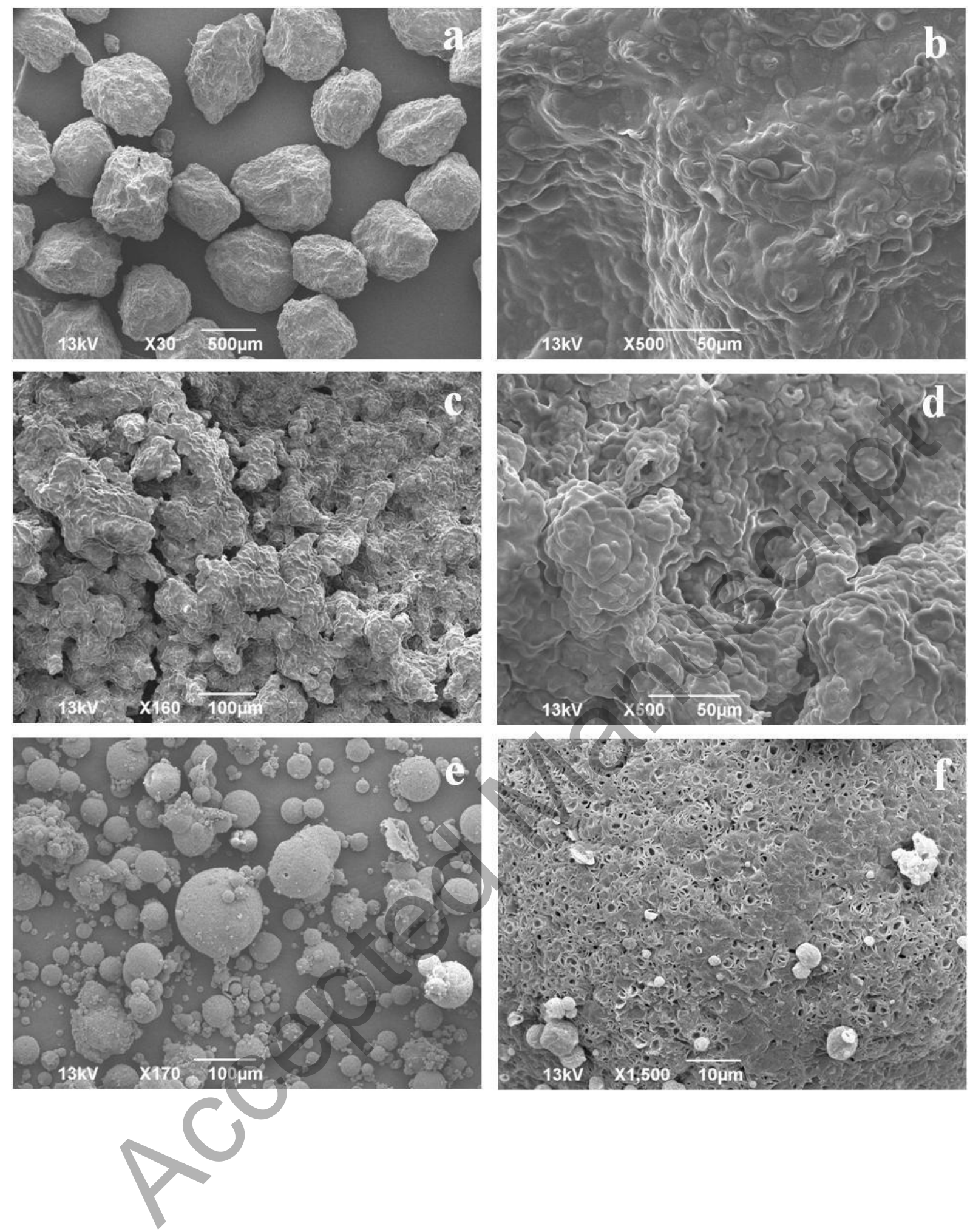


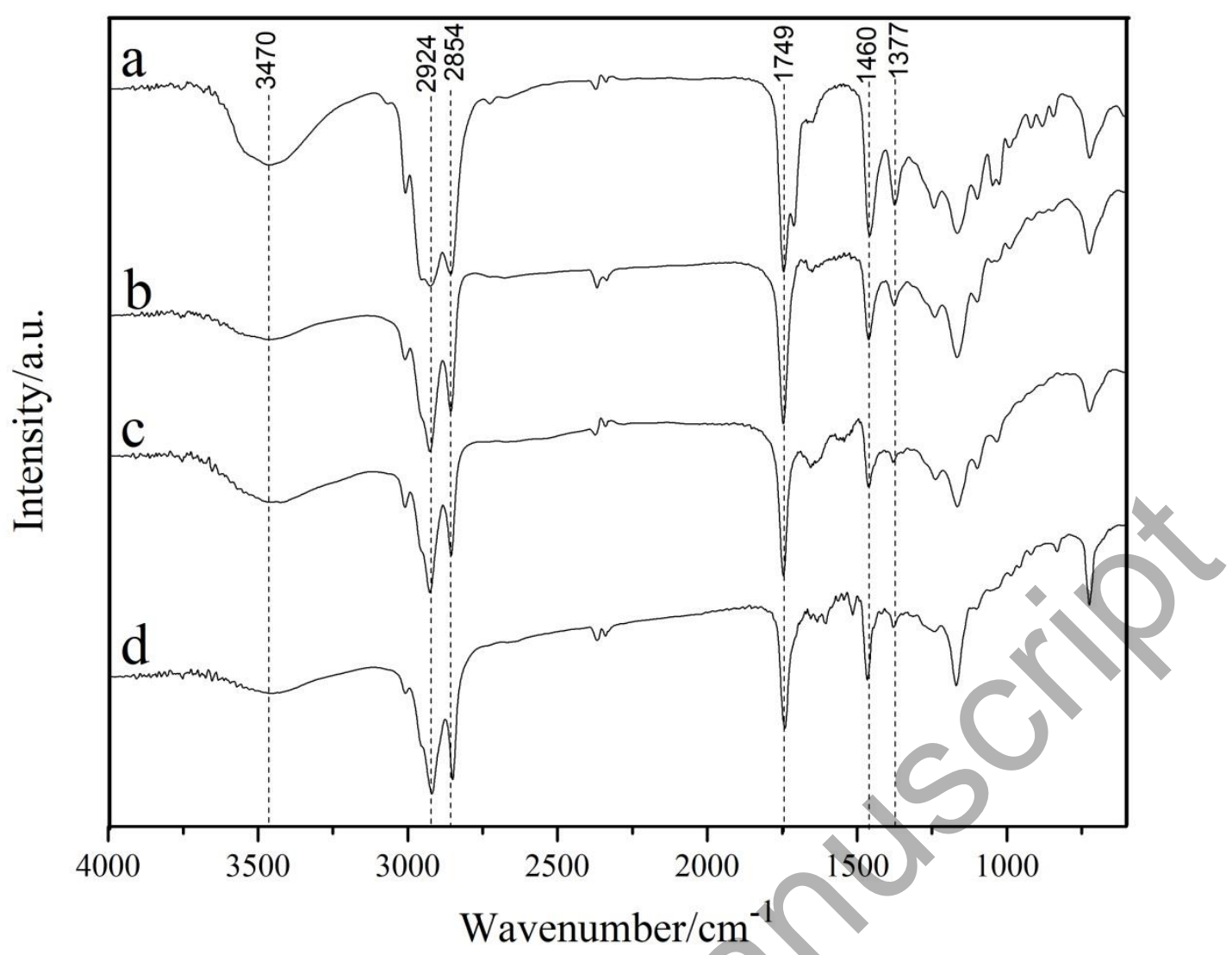



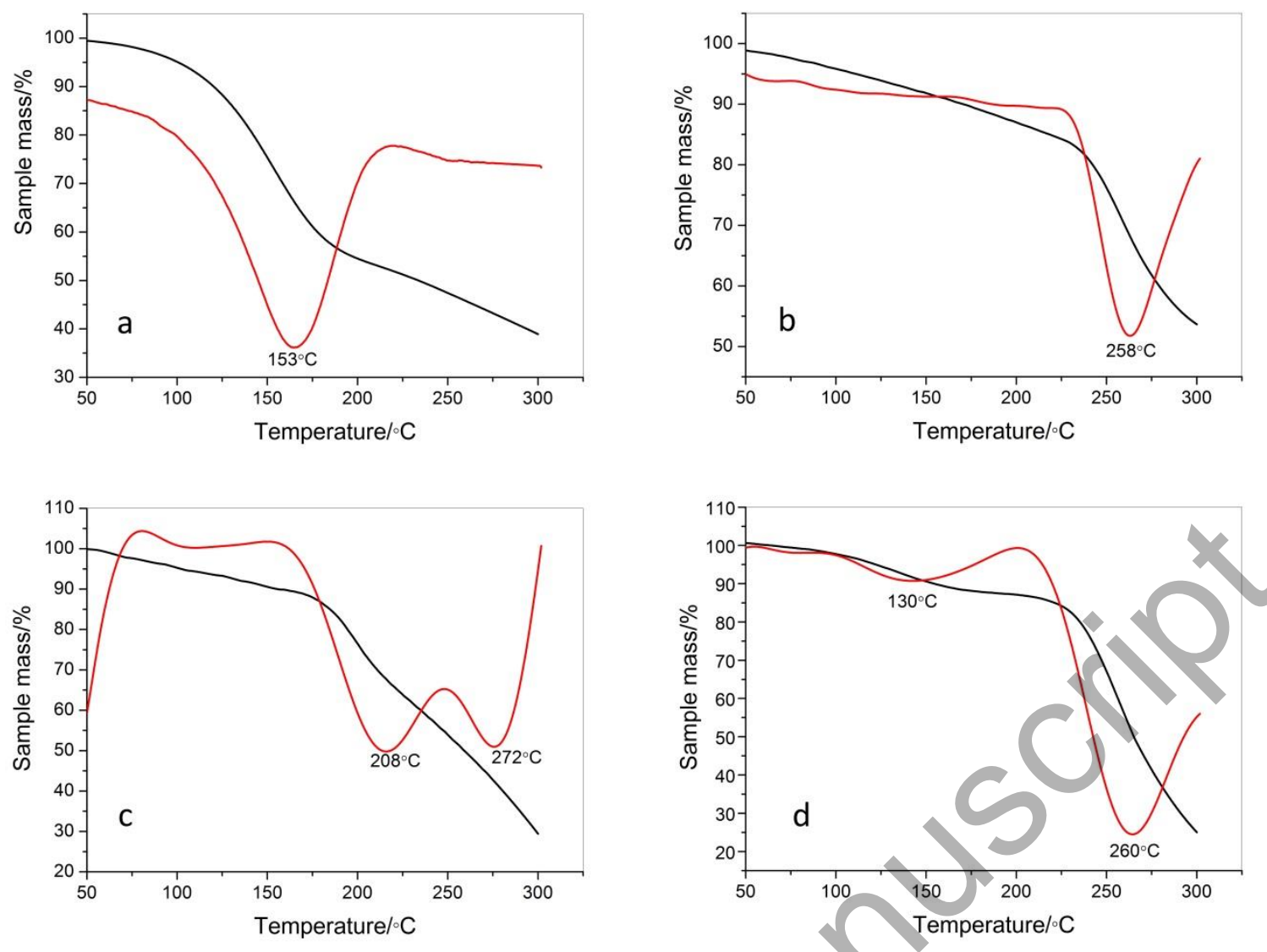


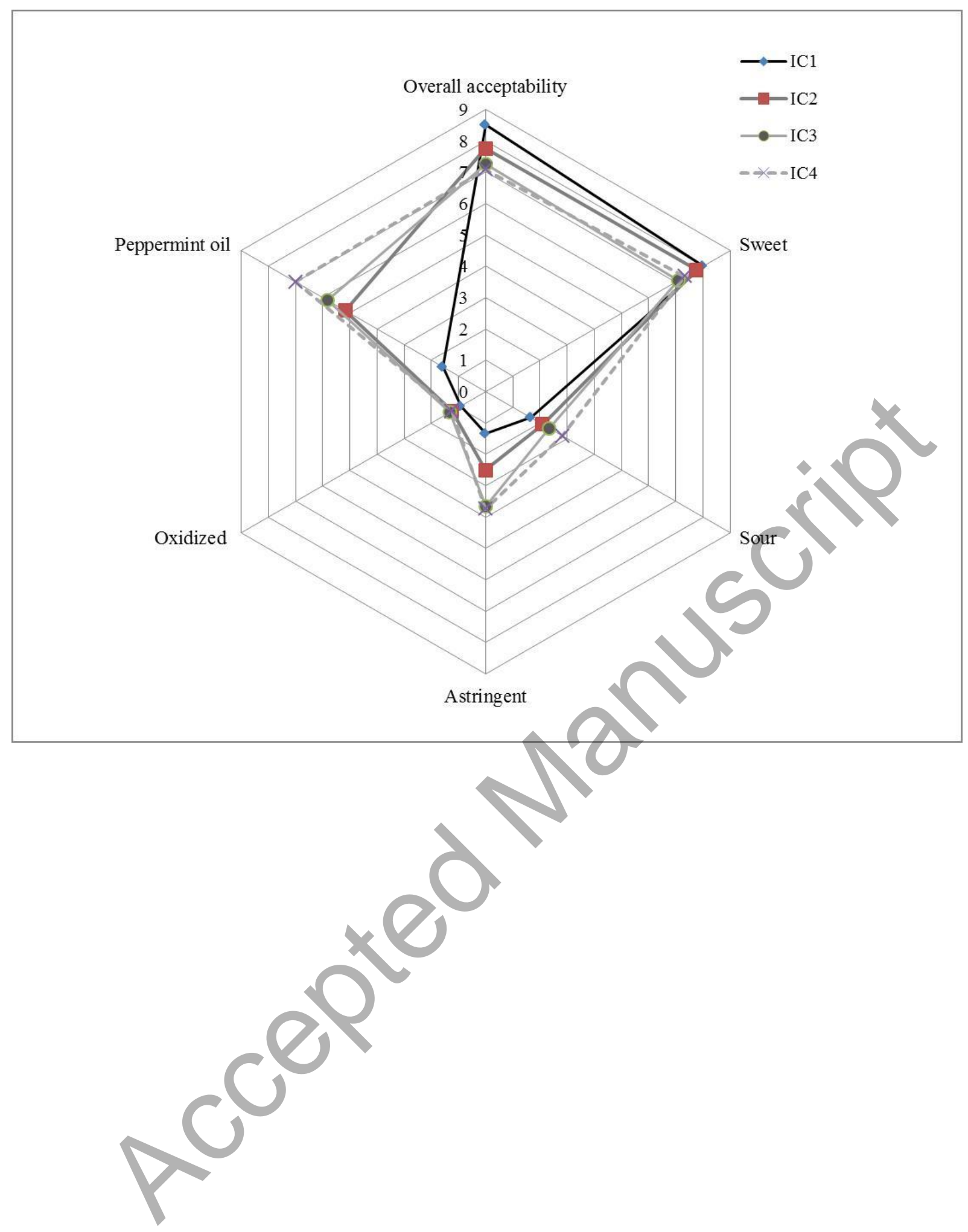


Table 1. Chemical composition of peppermint essential oil

\begin{tabular}{lc}
\hline Compound & $\%$ \\
\hline$\alpha$-pinene & 7,55 \\
camphene & 0,23 \\
$\beta$-pinene & 8,56 \\
sabinene & 0,24 \\
$\beta$-myrcene & 0,76 \\
limonene & 9,50 \\
1,8-cineole & 0,88 \\
$\beta$-cymene & 0,27 \\
3-octanol & 0,64 \\
$p$-menthone & 14,89 \\
$\beta$-bourbonene & 0,83 \\
linalool & 0,37 \\
1-octanol & 0,51 \\
menthyl acetate & 8,54 \\
isopulegol & 4,30 \\
longifolene & 0,19 \\
$\alpha$-ylangene & 0,39 \\
neomenthol & 6,98 \\
$\beta$-caryophyllen & 1,31 \\
neoisomenthol & 1,24 \\
menthol & 20,31 \\
pulegone & 1,83 \\
lavandulol & 0,61 \\
$\alpha$-terpineol & 6,09 \\
piperitone & 2,98 \\
total & 100 \\
\hline & \\
&
\end{tabular}


Table 2. Descriptive terms, definition, and reference material used for the training of the panelists $^{\mathrm{a}}$

\begin{tabular}{|c|c|c|}
\hline Sensory attribute & Definition & Reference material \\
\hline Overall acceptability & $\begin{array}{l}\text { Ice cream has no defects. } \\
\text { Sensorial properties are well } \\
\text { balanced. }\end{array}$ & $\begin{array}{l}\text { A commercial ice cream } \\
\text { (Algida Maraş Usulü, } \\
\text { Istanbul, Turkey) }\end{array}$ \\
\hline Sweet & $\begin{array}{l}\text { The intensity of flavor } \\
\text { caused by sucrose is clearly } \\
\text { perceivable }\end{array}$ & $2.0 \%(\mathrm{w} / \mathrm{v})$ sucrose solution \\
\hline Sour & $\begin{array}{l}\text { It is characterized by a } \\
\text { refreshing and fruity flavor. }\end{array}$ & $\begin{array}{l}\text { A commercial sorbet } \\
\text { (Algida, Istanbul, Turkey). }\end{array}$ \\
\hline Astringent & $\begin{array}{l}\text { Astringency sensation is dry } \\
\text { and gives a puckery feeling } \\
\text { in the mouth. }\end{array}$ & $\begin{array}{l}0.5 \%(\mathrm{w} / \mathrm{v}) \text { punicalagin } \\
\text { solution. }\end{array}$ \\
\hline Oxidized & $\begin{array}{l}\text { Off-flavor is characterized } \\
\text { by acardboard, papery and } \\
\text { tallow flavor and smell. }\end{array}$ & $\begin{array}{l}\text { Cream was oxidized at } 105 \\
{ }^{\circ} \mathrm{C} \text { for } 2 \mathrm{~h} \text { and an ice cream } \\
\text { mix was prepared with } \\
\text { oxidized cream. }\end{array}$ \\
\hline Overall peppermint flavor & $\begin{array}{l}\text { Sweet, green, earty, sharp, } \\
\text { mentholic aromatics } \\
\text { associated with peppermint } \\
\text { oil. }\end{array}$ & $\begin{array}{l}\text { Peppermint oil (Arifoğlu } \\
\text { Baharat, Istanbul, Turkey) }\end{array}$ \\
\hline
\end{tabular}


Table 3. Average bead size and encapsulation efficiency of peppermint essential oil encapsulates

\begin{tabular}{|c|c|c|}
\hline Preparation & Bead size $(\mu \mathrm{m})$ & Encapsulation efficiency (\%) \\
\hline \multicolumn{3}{|c|}{ Calcium alginate beads } \\
\hline A1 & $693.5 \pm 133.6 \mathrm{a}$ & $98.4 \pm 4.3 \mathrm{a}$ \\
\hline $\mathrm{A} 2$ & $827.2 \pm 121.5 \mathrm{a}$ & $96.5 \pm 5.5 \mathrm{a}$ \\
\hline \multicolumn{3}{|c|}{$\begin{array}{l}\text { Gelatin and alginate } \\
\text { coecervates }\end{array}$} \\
\hline $\mathrm{C} 1$ & - & $13.2 \pm 1.2 \mathrm{c}$ \\
\hline $\mathrm{C} 2$ & - & $11.8 \pm 1.0 \mathrm{c}$ \\
\hline $\mathrm{C} 4$ & - & $10.5 \pm 0.8 \mathrm{c}$ \\
\hline \multicolumn{3}{|c|}{ Carnauba wax beads } \\
\hline CW1 & $27.6 \pm 15.4 b$ & $66.8 \pm 4.7 b$ \\
\hline CW2 & $37.1 \pm 18.7 b$ & \\
\hline CW3 & $21.7 \pm 10.9 b$ & \\
\hline CW4 & $30.4 \pm 14.5 b$ & $94.2 \pm 7.8 \mathrm{a}$ \\
\hline \multicolumn{3}{|c|}{$\begin{array}{l}\text { A1: } 2 \mathrm{~g} \text { oil }+18 \mathrm{~g} \text { sodium alginate, } \mathrm{A} 2: 4 \mathrm{~g} \text { oil }+16 \mathrm{~g} \text { sodium alginate, } \mathrm{C} 1: 1 \mathrm{~g} \text { oil }+50 \mathrm{~g} \\
\text { polymer, } \mathrm{C} 2: 2 \mathrm{~g} \text { oil }+50 \mathrm{~g} \text { polymer, } \mathrm{C} 4: 4 \mathrm{~g} \text { oil }+50 \mathrm{~g} \text { polymer, CW1: } 1 \mathrm{~g} \text { oil }+9 \mathrm{~g} \\
\text { carnauba wax, } \mathrm{CW} 2: 2 \mathrm{~g} \text { oil }+8 \mathrm{~g} \text { carnauba wax, CW3: } 3 \mathrm{~g} \text { oil }+7 \mathrm{~g} \text { carnauba wax, CW4: } 5 \\
\mathrm{~g} \text { oil }+5 \mathrm{~g} \text { carnauba wax. In the same column, means with different letters significantly } \\
\text { differed }(P<0.05) \text {. }\end{array}$} \\
\hline
\end{tabular}

